\title{
DIAGNÓSTICO DA ARBORIZAÇÃO URBANA DO MUNICÍPIO DE GUARABIRA-PARAÍBA
}

\author{
DIAGNOSTIC OF URBAN TREE PLANTING IN GUARABIRA TOWN, STATE OF PARAÍBA
}

\author{
Suelen Thaís da Silva* \\ Breno Henrique de Sousa*
}

\section{RESUMO}

Este trabalho teve como objetivo analisar qualitativamente a atual situação da arborização do município de Guarabira na Paraíba, Nordeste do Brasil, bem como servir como base para futuras melhorias na arborização da cidade. A pesquisa contemplou a arborização em cinco bairros da cidade, o que representa uma expressiva parcela do universo estudado. Dentre os diversos métodos de avaliação de impacto ambiental, além da observação de mapas e imagens de satélite, optou-se pelo uso da Matriz de Leopold, muito comum para estudos de impacto ambiental da agricultura, e que permite uma interação entre as ações provenientes do projeto - neste caso, 0 estado da arte da arborização municipal - sobre os fatores do meio. Entre os diversos problemas observados, pode-se destacar a baixa diversidade de plantas e a predominância de espécies exóticas que são decorrentes da falta de planejamento que resultam em uma arborização desordenada, inapropriada e descontínua.

Palavras-chave: Planejamento territorial urbano. Meio ambiente urbano. Impactos ambientais.

\begin{abstract}
This study aimed to qualitatively analyze the current situation of urban tree planting in Guarabira Town, State of Paraiba, Northeast Brazil, as well as serve as a basis for future improvements in the city's urban forestry. The research looked at the urban forestry in five different neighborhood of the city, which represents an expressive part of the studied universe. Among the various methods of environmental impact assessment, in addition to the observation of maps and satellite images, we opted for the use of the Leopold Matrix, very common for environmental impact studies of agriculture and which allows interaction between the actions from the project - in this case, the current condition of municipal urban forestry - on environmental factors. Among the various problems observed, we can highlight the low diversity of plants and the predominance of exotic species that result from the lack of planning that result in a disorderly urban forestry, inappropriate and discontinuous.
\end{abstract}

Keywords: Urban territorial planning. Urban environment. Environmental impacts.

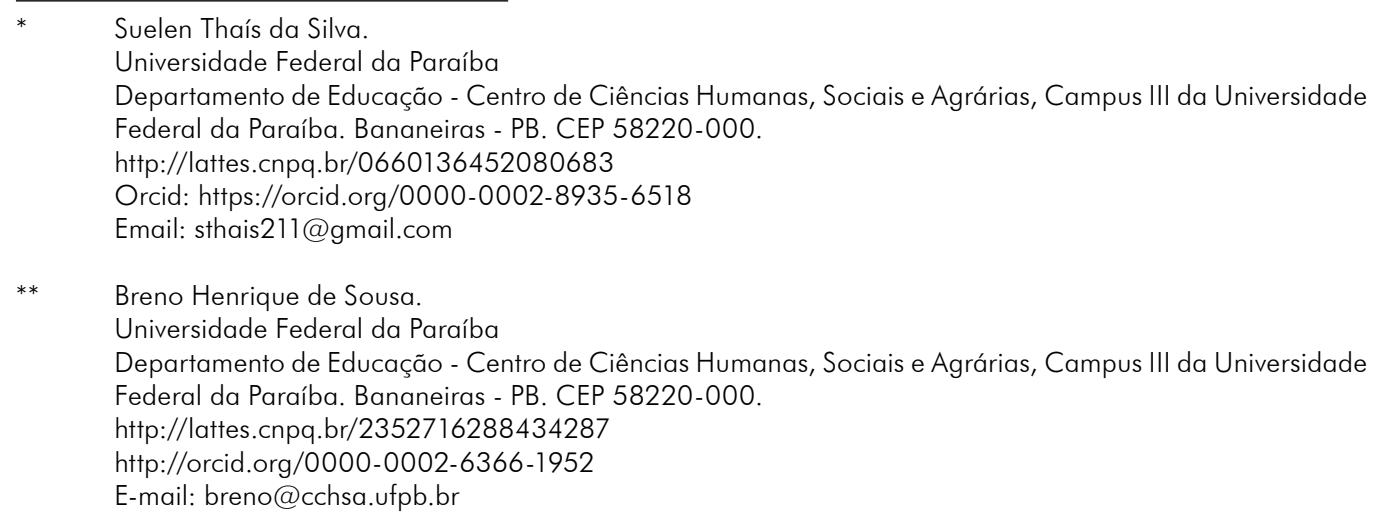




\section{INTRODUÇÃO}

Com o decorrer dos anos, observa-se que o homem vem migrando do meio rural para os grandes centros urbanos. De acordo com o censo realizado pelo IBGE (2014), 84\% da população do país vive nas cidades e a tendência é de aumento desse percentual.

As pressões resultantes dessa migração constante e crescente, frequentemente resultam em devastação de áreas verdes em um curto espaço de tempo. A composição vegetal vem desaparecendo dos centros urbanos através de ações antrópicas, dando lugar a áreas edificadas que impermeabilizam o solo. A supressão das áreas verdes por áreas edificadas torna as cidades cada vez mais quentes, afetando a qualidade de vida (FARAH, 1999), isso se dá pela diferença existente entre as características térmicas dos materiais de construção e da vegetação (SHAMS, GIACOMELI e SUCOMINE, 2009).

A rápida expansão das cidades, quando não contempla um planejamento adequado de ocupação, resulta em vários problemas ambientais que interferem diretamente na qualidade de vida dos seus cidadãos. A qualidade de vida urbana está diretamente atrelada a vários fatores que estão reunidos na infraestrutura, no desenvolvimento socioeconômico e àqueles ligados a questão ambiental. No caso do ambiente urbano, as áreas verdes públicas são elementos imprescindíveis para o bem-estar da população, pois influenciam diretamente na sua saúde física e mental (LOBODA \& DE ANGELIS, 2005).

Dessa forma, é necessário que se busque meios de diminuir o impacto ambiental decorrente da expansão destrutiva das cidades. $O$ paisagismo, que apresenta a arborização urbana como uma de suas possibilidades, surge como alternativa viável que pode ser utilizada para melhorar a qualidade ambiental do meio urbano.

Segundo Sanchotene (1994), entendese por arborização urbana o conjunto de vegetação arbórea natural ou cultivada que uma cidade apresenta. Essa vegetação está representada em áreas particulares, parques, praças, vias públicas e em outros espaços verdes complementares.

A vegetação desempenha funções essenciais em áreas urbanas, sobretudo aquelas com maior adensamento construtivo. Do ponto de vista ambiental, além do benefício térmico e microclimático já mencionado, melhora o ambiente urbano por meio da capacidade de produzir sombra, melhorando a qualidade do ar, aumentando o teor de oxigênio e de umidade, e absorvendo o gás carbônico, entre outras vantagens (GRAZIANO, 1994).

Desse modo, a arborização urbana é essencial em qualquer planejamento urbano por suas inúmeras funções que contribuem para melhorar a qualidade de vida da população, já que as árvores amenizam os efeitos prejudiciais causados pelo meio urbano.

Apesar de que muito da história da arborização tenha se perdido ao longo dos anos, ao olhar para a história e evolução humana, é possível perceber que desde os primórdios a arborização vem sendo utilizada para proporcionar conforto e bem-estar aos que dela desfrutavam. 
Para Segawa (1996), a história da arborização urbana e sua evolução teve seu início e desenvolvimento por volta do século XV na Europa, sendo que sua prática se tornou comum a partir do século XVII. Naquela época foram criados os passeios ajardinados onde se utilizavam as espécies floríferas como principais elementos caracterizadores. Desse modo, podemos compreender que as áreas verdes estão ligadas ao homem desde muito tempo. Para alguns homens da antiguidade, a vegetação estava ligada à sobrevivência, uma vez que alimentos eram retirados delas.

No Brasil, a arborização de ruas passou a fazer parte do planejamento urbano de forma generalizada somente no final do século XIX, associada ao advento da república, período no qual a arborização urbana teve um bom desenvolvimento (MENEGHETTI, 2003).

De acordo com Santos e Teixeira (2001), a maioria das cidades brasileiras apresenta um cenário onde as paisagens florísticas são pouco diversificadas com predomínio das espécies exóticas, em detrimento das possibilidades de se explorar a riqueza da flora local.

Podemos assim tomar como exemplos espécies como: Ficus benjamina (Fícus), Azadirachta indica (Nim), Mangifera indica (Mangueira) e Eucalyptus ssp. (Eucalipto), todas árvores exóticas, mas que no Brasil estão bastante disseminadas nas áreas urbanas. Algumas foram introduzidas com o objetivo de exploração econômica, é o caso do eucalipto, que é a principal fonte de matéria prima para a produção de celulose. Porém, o nosso país apresenta uma vasta diversidade de espécies arbóreas, e nesse sentido já existem no Brasil projetos de arborização urbana que favorecem as espécies nativas de cada região.

A arborização urbana planejada e racional é uma necessidade imprescindível à qualidade de vida da população, sobretudo nas grandes metrópoles onde a polvição é maior e precisa ser amenizada (CEMIG, 2011), porém, a obtenção dos benefícios da arborização está diretamente ligada à qualidade da mesma.

É importante destacar que a arborização urbana deve ser orientada por critérios técnicos, que quando não seguidos causa prejuízos econômicos e danos ao ambiente. As árvores plantadas em locais inadequados danificam a infraestrutura urbana, afetando casas e muros, bem como as redes elétrica e hidráulica. Dessa forma, a ausência de planejamento na arborização urbana causa impactos ambientais e sob a essa perspectiva, pode-se avaliar qualitativamente o estado da arte da arborização municipal, ou seja, pode-se verificar os prejuízos causados pela má arborização de acordo com a presença inadequada ou ausência de árvores.

Nesse viés, segundo o Art.1 da Resolução CONAMA 01/86 (BRASIL, 1986), pode-se definir impacto ambiental "como qualquer alteração das propriedades físicas, químicas e biológicas do meio ambiente, causada por qualquer forma de matéria ou energia resultante das atividades humanas que, direta ou indiretamente, afetam a saúde, a segurança e o bem-estar da população, as atividades sociais e econômicas, a biota, as condições estéticas e sanitárias do meio ambiente e a qualidade dos recursos ambientais ${ }^{1 \prime \prime}$.

É sob esta definição que consideramos os impactos que a ausência da arborização urbana, ou a sua presença desordenada pode provocar sobre o meio ambiente urbano. 
Nos primeiros anos de utilização, os estudos voltados para a análise de impactos ambientais centravam-se nos aspectos físico-naturais, e eram empregados em áreas geralmente não urbanizadas. Hoje esses estudos são aplicados a todos os ramos de atividade humana e suas ferramentas permitem identificar processos de degradação ambiental, tipifica-los, categorizá-los, ponderá-los, orientando a gestão racional e tomada de decisões. Essas ferramentas são bastante utilizadas no meio acadêmico, em Estudos de Impacto Ambiental (EIA) e como ferramentas de gestão e controle da qualidade no âmbito das decisões empresariais e industriais (CAMPOS, 1992; DELLARETTI, 1996).

Por isso, acredita-se que as metodologias utilizadas nos estudos de impacto ambiental possuem potencial para serem aplicadas no âmbito da arborização urbana, especialmente para orientar intervenções corretoras onde a arborização se deu de forma deficiente ou não planejada.

Algumas dessas ferramentas como: redes de interações, método ad hoc, listagens de controle, matrizes de interação, dentre outras, são de uso prático e demandam poucos recursos para a sua aplicação. Podem também ser usadas pelo poder público para priorização da aplicação de recursos e planejamento de ações de intervenção. Outra vantagem é que essas ferramentas permitem a participação de especialistas de diversas áreas, podendo ainda integrar a comunidade na tomada de decisões, dando um caráter mais participativo e democrático a todo o processo.

Diante disso, este trabalho teve como objetivo analisar qualitativamente a atual situação da arborização município de Guarabira - PB. Para tanto, utilizou-se a Matriz de Leopold (LEOPOLD, et al. 1971), ferramenta amplamente utilizada em Estudos de Impacto Ambiental (EIA). Espera-se que esta abordagem inicial provoque contribuições vindouras, permitindo o avanço e aperfeiçoamento do uso dessas metodologias no campo da arborização urbana.

\section{MATÉRIAL E MÉTODOS}

Este trabalho foi realizado na sede municipal de Guarabira - Paraíba, que possui uma área total de 165,74 km² e uma área urbana de $6 \mathrm{~km}^{2}$ (IBGE, 2014). Diante da inviabilidade de inventariar o estado da arborização de todos os logradouros municipais, optou-se pela realização de uma amostragem qualitativa seguindo os princípios de 'diversificação e saturação' propostos por Pires (2010).

Esse procedimento foi realizado a partir de uma exaustiva verificação in loco do estado da arborização da sede municipal considerando os diversos bairros da cidade (diversificação). Nessa etapa os pesquisadores fizeram registros fotográficos, medições e anotações sobre características gerais e problemas comuns até o limite de saturação, que corresponde ao momento em que os dados tornam-se repetitivos. Esta primeira etapa consiste também em uma análise exploratória, nela os pesquisadores percorrem os diversos bairros da cidade (com veículo próprio e a pé) para elaborar um perfil preliminar da arborização de cada bairro. Esse perfil não se trata de um inventário, mas uma lista de controle simples dos problemas mais frequentemente visualizados 
em cada bairro, a partir dela é possível escolher as áreas amostrais que refletem os aspectos predominantes da arborização urbana municipal.

A escolha definitiva dos bairros ou áreas específicas que comporão a amostragem para o trabalho deve ser representativa não apenas do ponto de vista de sua extensão física, correspondendo a uma expressiva parcela do universo estudado, mas deve também sê-lo no aspecto qualitativo, de forma que essas áreas equivalham em menor escala ao panorama geral encontrado no município. De nada valeria uma avaliação municipal feita apenas nos bairros nobres da cidade onde a arborização é mais abundante e bem planejada, ignorando a realidade frequentemente oposta das periferias.

Fazer uma análise exploratória até o limite da saturação de informações possibilitando a escolha de áreas amostrais representativas torna-se menos difícil em pequenos municípios como foi o caso desta pesquisa, mesmo assim, em grandes centros urbanos esta metodologia poderá ser utilizada por bairro, divididos em setores específicos conforme as características de sua arborização. A disponibilidade de tempo, recursos humanos especializados e financeiros e integração com a comunidade serão os fatores que determinarão a abrangência geográfica deste tipo de avaliação. É importante também a participação da população na elaboração de um perfil preliminar. Neste trabalho não contamos com essa participação direta, porém a autora principal é natural do município estudado o que contribuiu nas diversas etapas do estudo.

Atingir o ponto de saturação das informações é algo que também deve ser assegurado através de procedimentos complementares, garantindo que as observações realizadas foram suficientes. Por isso, utilizaram-se imagens de satélite através do sof-

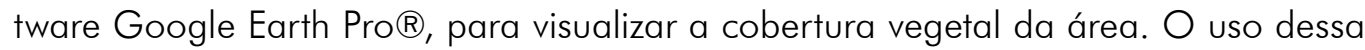
ferramenta permite identificar rapidamente em quais logradouros há maior ou menor concentração de cobertura vegetal. Essas áreas são incluídas no roteiro de visitas para em seguida serem qualificadas conforme suas características.

Outro procedimento complementar foi a realização de uma entrevista aberta com Alcides Camilo de Moura Sobrinho, secretário do meio ambiente e saneamento da cidade de Guarabira entre os anos de 2014 e 2017 sobre a arborização urbana da cidade.

A partir dos procedimentos explicados escolheram-se os bairros avaliados nesta pesquisa. A escolha contemplou áreas centrais e periféricas que abrangessem a heterogeneidade da arborização da cidade. Os bairros escolhidos foram: Bairro Novo $\left(0,83 \mathrm{~km}^{2}\right)$; Centro $\left(0,56 \mathrm{~km}^{2}\right)$; Esplanada $\left(0,19 \mathrm{~km}^{2}\right)$; Nordeste $\left(0,45 \mathrm{~km}^{2}\right)$ e São José $\left(0,31 \mathrm{~km}^{2}\right)$. Juntos esses bairros somam $2,34 \mathrm{~km}^{2}$, o que corresponde ao expressivo percentual de $39 \%$ da área urbana municipal (Figura 1).

Para avaliar a qualidade da arborização da cidade, considerou-se critérios técnicos de arborização estabelecidos em manuais de arborização urbana como o que foi elaborado pela CEMIG (2011). Nesse manual encontram-se normas técnicas que permitem aferir quando a arborização está estabelecida de forma inadequada, causando prejuízos na infraestrutura urbana, na circulação de veículos e pedestres, ou 
comprometendo a harmonia da paisagem. No manual são estabelecidos, por exemplo, a localização correta para plantar uma árvore em um passeio público ou logradouro, o espaçamento correto entre árvores, bem como o espaçamento entre árvores e estruturas urbanas como prédios, residências, esquinas, pontos de iluminação, etc. Diversas espécies também são definidas a partir de seu porte (pequeno, médio ou grande) e recomendadas conforme essa característica. Também existem normas para realizar podas nas árvores de maneira que é possível identificar quando essas podas foram realizadas de forma tecnicamente correta ou não.

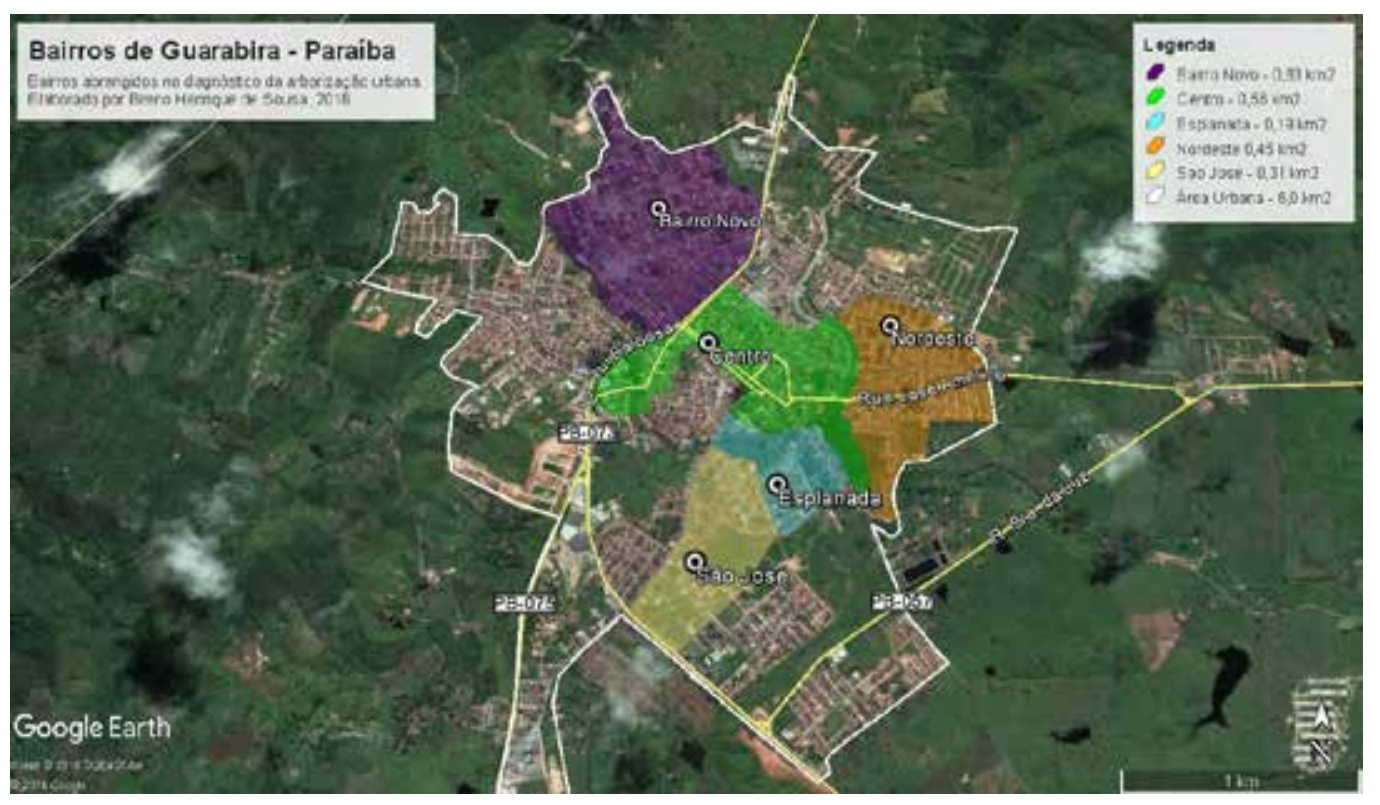

Figura 1 Mapa dos bairros escolhidos para avaliação da arborização urbana na cidade de Guarabira - PB. Composto através do software Google Earth Pro em 2016 e processado por Breno Henrique de Sousa.

A partir do conhecimento técnico essencial sobre o tema, estabeleceram-se vinte e duas características a serem observadas na arborização. Algumas dessas características, conforme se vê adiante, denunciam claramente um aspecto inadequado ou deficitário da arborização, outras características podem ser consideradas positivas ou negativas conforme a sua interação com o ambiente. As características estabelecidas foram:

1. Ausência de árvores - aspecto ponderado negativamente que deve ser acompanhado da explicação da possível causa da ausência de arborização. A estrutura local não permite a implantação de árvores? Não há iniciativa do poder público? A comunidade local não parece receptiva à implantação de árvores? Indicar as possíveis causas permitirá uma intervenção específica ou, se for necessário, um estudo mais aprofundado;

2. Pequena quantidade de árvores - neste caso cabem as mesmas observações feitas para o item anterior. 
3. Excesso de árvores - o excesso de árvores em uma via pública pode comprometer a harmonia da paisagem, prejudicar a visualização de placas de sinalização ou a iluminação noturna, mesmo quando essas árvores estão plantadas dentro de um espaçamento correto e não estão em conflito com a infraestrutura urbana. Neste caso será necessária uma intervenção técnica para equilibrar os elementos da paisagem.

4. Espaçamento adensado - árvores plantadas em pequeno espaçamento podem causar prejuízos à paisagem e à infraestrutura urbana, o espaçamento ideal é de sete metros entre árvores de médio e grande porte (CEMIG, 2011).

5. Baixa diversidade - o uso de uma ou poucas espécies empobrece a paisagem tornando-a monótona, além disso, uma arborização pouco diversificada é mais vulnerável ao ataque de pragas e doenças.

6. Local de plantio inadequado - significa que as árvores foram plantadas em local inadequado, não respeitando o distanciamento correto entre prédios, calçadas, tubulações hidráulicas e redes elétricas.

7. Raízes provocando danos - esse aspecto geralmente está associado ao item anterior e ocorre também pelo uso de árvores de grande porte em pequenos logradouros (ver o item 16). Neste caso é possível observar diretamente os danos decorrentes do crescimento arbóreo, como o rompimento do pavimento, tubulações e rede elétrica subterrânea.

8. Podas não realizadas - a ausência de podas pode prejudicar a paisagem e a infraestrutura mesmo quando as árvores estão corretamente posicionadas.

9. Podas mal realizadas - neste caso observam-se árvores deformadas que perderam seu valor paisagístico e ornamental. É muito comum em situações onde se tenta adequar árvores de grande porte em pequenos espaços. As podas mal realizadas também causam feridas em troncos e galhos que deixam a árvore vulnerável à contaminação por pragas e doenças.

10. Árvores danificadas (vandalismo) - refere-se a árvores queimadas parcialmente, contaminadas propositalmente, troncos com placas e propagandas apregoadas ou talhados com escrituras.

11. Troncos caiados - o uso da cal virgem para pintar os troncos de árvores ainda é uma prática comum nas cidades brasileiras. Essa prática além de comprometer a paisagem, prejudica a saúde da árvore. A ação cáustica da cal virgem elimina a microbiota existente no tronco das árvores, essa microbiota tem função importante na proteção natural da planta.

12. Pragas e doenças - árvores visivelmente afetadas por pragas e doenças que comprometem seu valor paisagístico ou a sua própria sobrevivência. Em alguns casos, determinados insetos podem também ser um inconveniente para os cidadãos.

13. Pequena área de infiltração - ocorre quando as árvores estão estranguladas pelo pavimento não permitindo que a água da chuva ou das regas se infiltre no solo. Essa situação pode comprometer a sobrevivência da planta, além de impedir o reabastecimento do lençol freático e contribuindo com a formação de enxurradas pelo escoamento superficial da água não infiltrada. 
14. Risco de tombamento ${ }^{2}$ - árvores que estão sob o risco de tombamento devido à incidência de pragas como cupins, erosão do solo ou qualquer outro fator. Este caso específico deve ser notificado ao poder público evitando prejuízos e acidentes. Em alguns casos essa situação pode representar risco de vida aos transeuntes.

15. Porte reduzido para o local - árvores de pequeno porte são adequadas para logradouros com passeios estreitos ou pequenos jardins, porém, em vias mais amplas convém aproveitar os benefícios de uma arborização composta por espécies mais frondosas e de maior porte, especialmente em regiões mais quentes e com alta radiação solar. Neste caso, não se trata de uma irregularidade técnica, mas apenas uma orientação para futuras intervenções paisagísticas.

16. Porte avantajado para o local - este aspecto refere-se especificamente ao uso de árvores de grande porte em pequenos espaços, logradouros e passeios estreitos. Esta característica foi destacada de forma particular por sua grande incidência na área estudada.

17. Árvores frutíferas; 18. Árvores floríferas; 19. Árvores sombreadoras; 20. Árvores raras ou de valor histórico; 21. Espécies exóticas; 22. Espécies nativas - essas características especiais são registradas permitindo intervenções específicas como a proteção legal de exemplares arbóreos no caso de espécies raras ou de valor histórico, ou mesmo para recomendações específicas, por exemplo, utilizar espécies sombreadoras e não frutíferas em áreas de estacionamento.

Após definir as características a serem observadas na arborização urbana municipal, esses itens são introduzidos na Matriz de Leopold (LEOPOLD, et al. 1971) modificada para avaliar as condições da arborização urbana do município.

Segundo Moreira (1992), as matrizes de interação permitem sistematizar de maneira esquemática um grande número de informações que contemplam diversas áreas do conhecimento. Um fator limitante dessas ferramentas é que as relações de causa e efeito nas matrizes e a ponderação dos impactos identificados é feita por uma equipe técnica multidisciplinar e o sucesso desse procedimento depende do conhecimento e habilidade desses avaliadores. Por outro lado, ao permitirem a visualização estratégica de uma grande quantidade de informações, as matrizes auxiliam a tomada de decisões e orientam a elaboração de políticas públicas e aplicação de recursos.

Segundo Ponce (2011), a Matriz de Leopold foi desenvolvida em 1971 em resposta à Lei de Política Ambiental dos Estados Unidos em 1969. Essa matriz é muito utilizada em Estudos de Impacto Ambiental e permite uma interação entre as ações provenientes de um projeto e os fatores do meio. O modelo original está baseado em uma matriz que apresenta 100 possíveis ações causadoras de impacto e 88 fatores susceptíveis de serem afetados, porém estas ações e fatores podem ser ajustados às necessidades específicas do projeto. 
O princípio básico da Matriz de Leopold consiste em, primeiramente, assinalar todas as possíveis interações entre as ações e os fatores, para em seguida ponderar a magnitude e a importância de cada impacto.

Uma vez detectadas e estabelecidas as relações ação/fator existentes, procedese uma avaliação individual das mesmas, considerando dois fatores fundamentais:

1. Magnitude - relação do fator específico com a ação praticada. Representa a alteração provocada no fator ambiental considerado (extensão ov escala do impacto). Pontua-se uma escala que vai de 1 a 10 onde 10 representa a máxima magnitude e 1 a mínima. Tal pontuação irá precedida do símbolo (+) se o impacto sobre o meio ambiente for positivo e do símbolo (-) se o impacto for negativo.

2. Importância - relação comparativa da importância desta ação com relação ao impacto provocado por outras ações. Mostra o peso relativo que o fator ambiental tem dentro do projeto, isto é, a ponderação que tem o impacto com relação aos outros. O valor numérico da importância está baseado no juízo objetivo da pessoa ou da equipe multidisciplinar que trabalhe no estudo. Também se qualifica de 1 a 10, sendo a última pontuação correspondente à interação mais importante. Tanto em magnitude como em importância, o valor zero não é válido.

Para avaliar quais os fatores da arborização que mais afetam o meio urbano, os cinco bairros (Bairro Novo, Centro, Esplanada, Nordeste e São José) foram analisados de acordo com os itens listados na Matriz de Leopold (Figura 2).

Para a aplicação da matriz neste trabalho, procedeu-se da seguinte forma: as 22 características da arborização são introduzidas na matriz com a denominação "condições da arborização que afetam o meio ambiente", que corresponde às ações de um projeto ambiental que impactam o meio ambiente (colunas da Figura 2). A Matriz de Leopold realiza um cruzamento entre as ações de um projeto e os fatores ambientais que podem ser afetados. Neste caso, a presença da arborização (ação) incide sobre os fatores do ambiente urbano (linhas da Figura 2).

$\mathrm{Na}$ intersecção entre ações e fatores (colunas $\mathrm{x}$ linhas), ponderou-se a importância e a magnitude de cada interação. O valor da "magnitude" é relativamente objetivo ou empírico, pois refere-se ao grau de alteração provocado pela ação sobre o fator ambiental, a pontuação da "importância" é subjetiva ou normativa, uma vez que envolve atribuição de peso relativo ao fator afetado no âmbito do projeto (COSTA, 2005).

Logo após, realizou-se um cálculo que consiste em multiplicar os valores de magnitude e importância obtidos para cada interação. Em seguida é feita uma média entre os valores obtidos para cada ação ou condição da arborização, obtendo-se assim um valor final que permite identificar os aspectos da arborização mais relevantes e que demandam intervenção.

Após a escolha das áreas amostrais e a elaboração da matriz, os pesquisadores retornam a campo munidos desse instrumento e percorrem todas as ruas de cada unidade amostral (bairro) preenchendo uma única matriz para cada bairro. Vale ressaltar que nesta situação específica, cada área tem pequena extensão e apresenta condições relativamente homogêneas. 


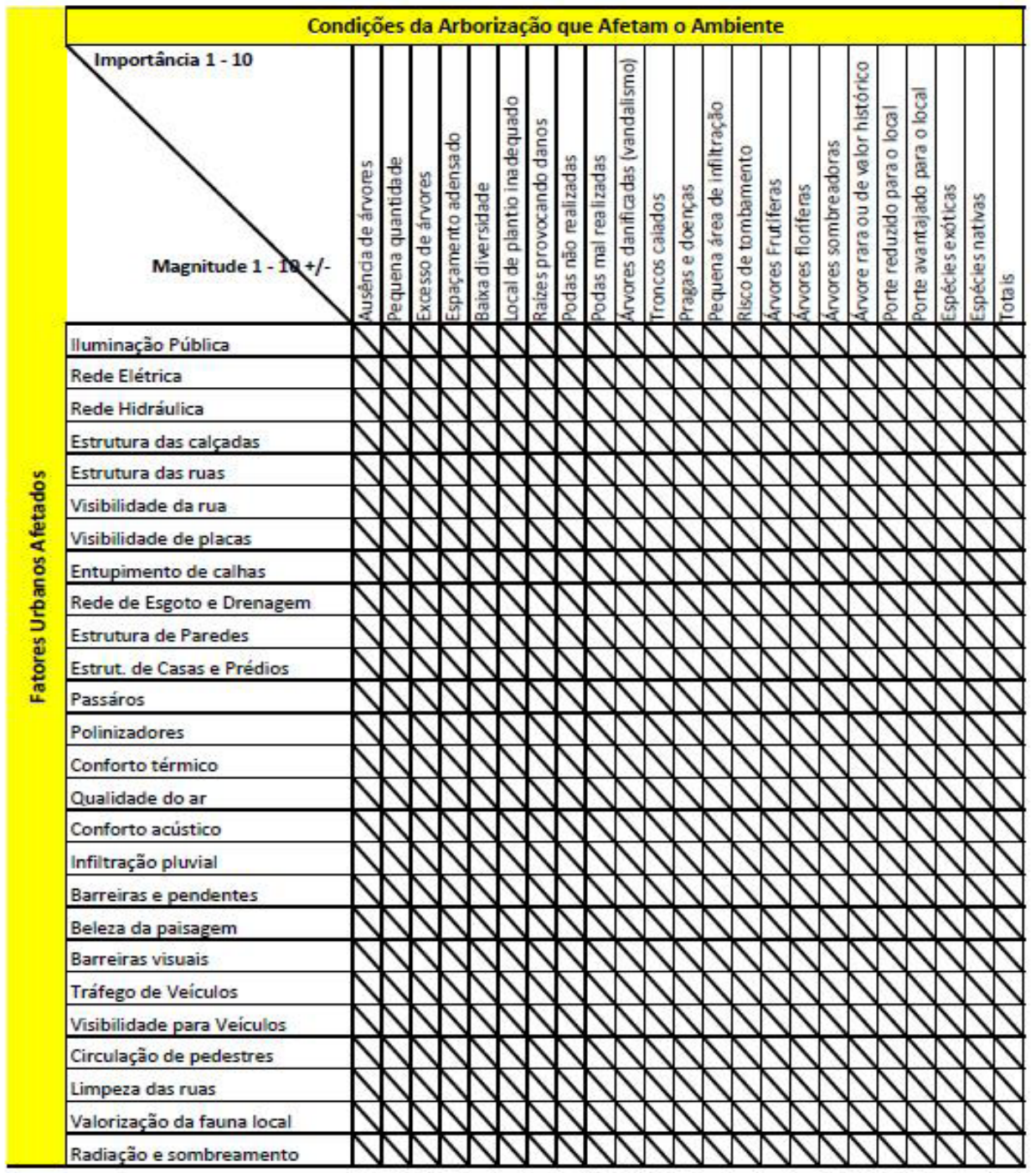

Figura 2 Matriz de Leopold modificada para avaliação ambiental da arborização do município de Guarabira - PB. Desenvolvido por Suelen Thais da Silva e Breno Henrique de Sousa, 2016.

As interações não ponderadas na matriz correspondem àquelas onde a característica da arborização não se relaciona com o fator ambiental específico. Esses espaços permanecem em branco conforme se observará adiante nos resultados.

\section{RESULTADOS E DISCUSSÃO}

No decorrer da pesquisa observou-se que a cidade é carente de arborização. As principais ruas e avenidas - localizadas no centro da cidade - estão bem arborizadas, mas, no entanto, nos bairros residenciais a arborização nas ruas é quase nula ou inexistente. Diante das imagens de satélite e das visitas foi possível observar que a maior parte das árvores existentes nos bairros residenciais estão localizadas nos quintais das casas. 
Um dos principais problemas observados é a falta de planejamento da arborização. Em entrevista aberta realizada com o Secretário do Meio Ambiente Alcides Camilo, a respeito do tema da arborização urbana na cidade, ele relata que a falta de planejamento é decorrente das gestões passadas, que as espécies existentes na cidade antes de sua nomeação teriam sido introduzidas aleatoriamente por moradores da cidade; afirma que antes de sua posse não existiam projetos nem preocupações voltadas para a arborização.

Segundo o Secretário, a prefeitura adquire mudas em uma cooperativa de produtores do município de Araruna na Paraíba. As espécies adquiridas se limitam àquelas que já são atualmente utilizadas na arborização municipal, ou seja, poucas espécies exóticas e algumas árvores frutíferas. As mudas adquiridas são levadas ao viveiro municipal de Guarabira onde são distribuídas gratuitamente para a população quando a mesma se dirige ao local, ou são utilizadas pela própria prefeitura para plantio e replantio nas ruas da cidade.

O que se observa in loco é que apesar da boa vontade do poder público, a prefeitura não dispõe de pessoal especializado. Não há nenhuma iniciativa para a diversificação de espécies ou valorização da flora local, as ações de arborização se limitam ao plantio ou distribuição de mudas, em alguns casos são utilizadas pequenas cercas de proteção para as mudas padronizadas com a logomarca da prefeitura. Essas ações são esporádicas e descontínuas, não sendo suficientes para estabelecer uma arborização urbana eficiente.

De acordo com Silva et al. (2008) a maioria das prefeituras dos municípios brasileiros não se preocupa com o planejamento da arborização e por isso, frequentemente, os próprios moradores realizam o plantio nas áreas públicas. Desse modo o padrão observado em muitas cidades brasileiras é de uma arborização irregular, inadequada e descontínua, ocorrendo em muitos casos o plantio de espécies exóticas. O panorama atual da arborização em Guarabira reflete exatamente esse quadro, onde as iniciativas do poder público são escassas ou insuficientes e a arborização ocorre com essas mesmas limitações.

As espécies arbóreas predominantes nas ruas do município estudado são o Ficus benjamina (Fícus), Azadirachta indica (Nim indiano) e a Senna siamea (CassiadeSião), com predominância do Fícus, o que torna a paisagem monótona. O Ficus benjamina, é uma espécie exótica nativa do sul e sudeste da Ásia que no Brasil se tornou largamente utilizada na arborização de ruas e jardins. Trata-se de uma espécie de grande porte, não sendo indicada para a arborização de ruas e avenidas.

\subsection{Problemática Encontrada na Arborização Municipal}

No decorrer do trabalho foram identificados problemas recorrentes na arborização, como: Podas mal feitas ou não realizadas; árvores "estranguladas" pela pavimentação, sem espaço para a infiltração de água; ou mesmo a baixa quantidade de árvores.

O plantio de espécies, que por seu grande porte são inadequadas para a arborização de logradouros, vem causando grandes danos à infraestrutura urbana. Verificou-se que as copas das árvores frequentemente estão em contato com a rede elétrica (Figura 3). 


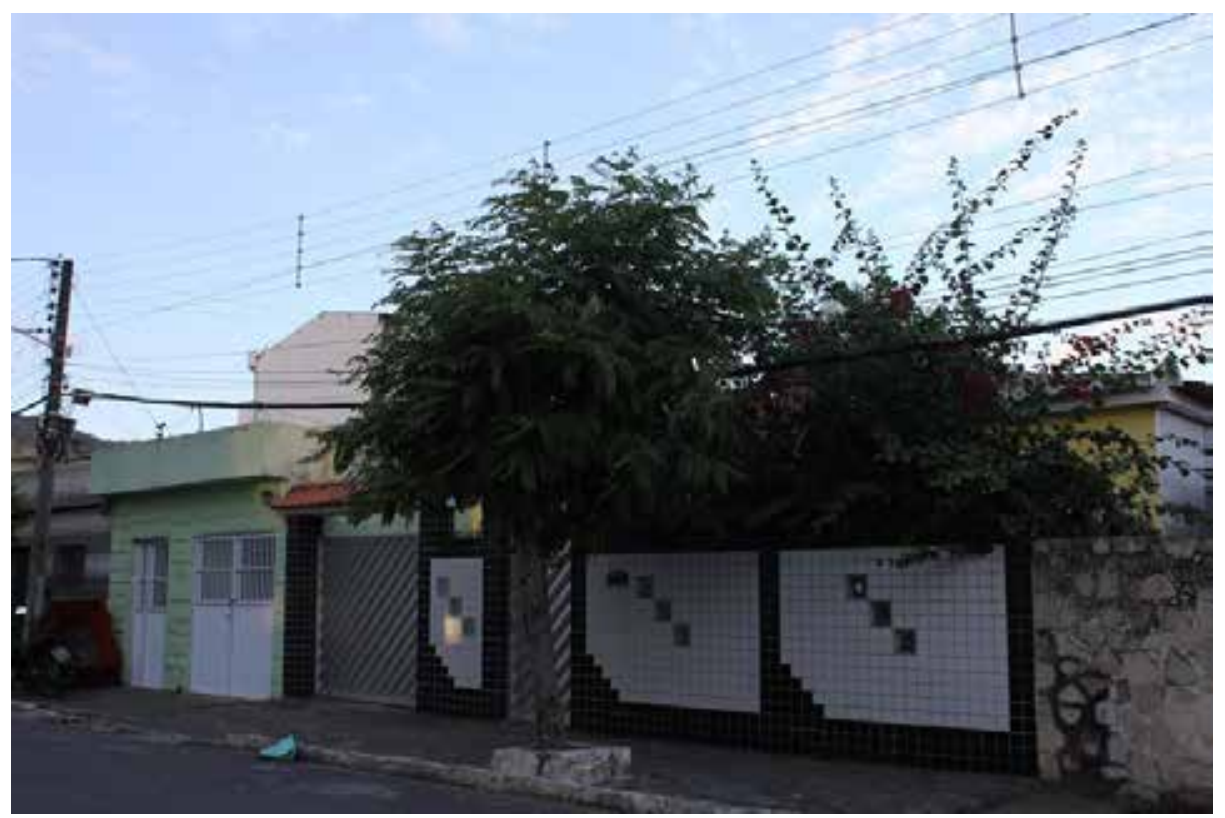

Figura 3 Copa da árvore em contato com a rede elétrica, em via pública de Guarabira - PB. Foto: Suelen Thais da Silva, 2016.

As árvores plantadas em locais inadequados conforme seus portes também acarretam problemas de rachadura na estrutura das calçadas, ruas e muros (Figura 4). Tal problema é ocasionado pelas características do sistema radicular vigoroso, sobretudo de espécies de crescimento rápido.

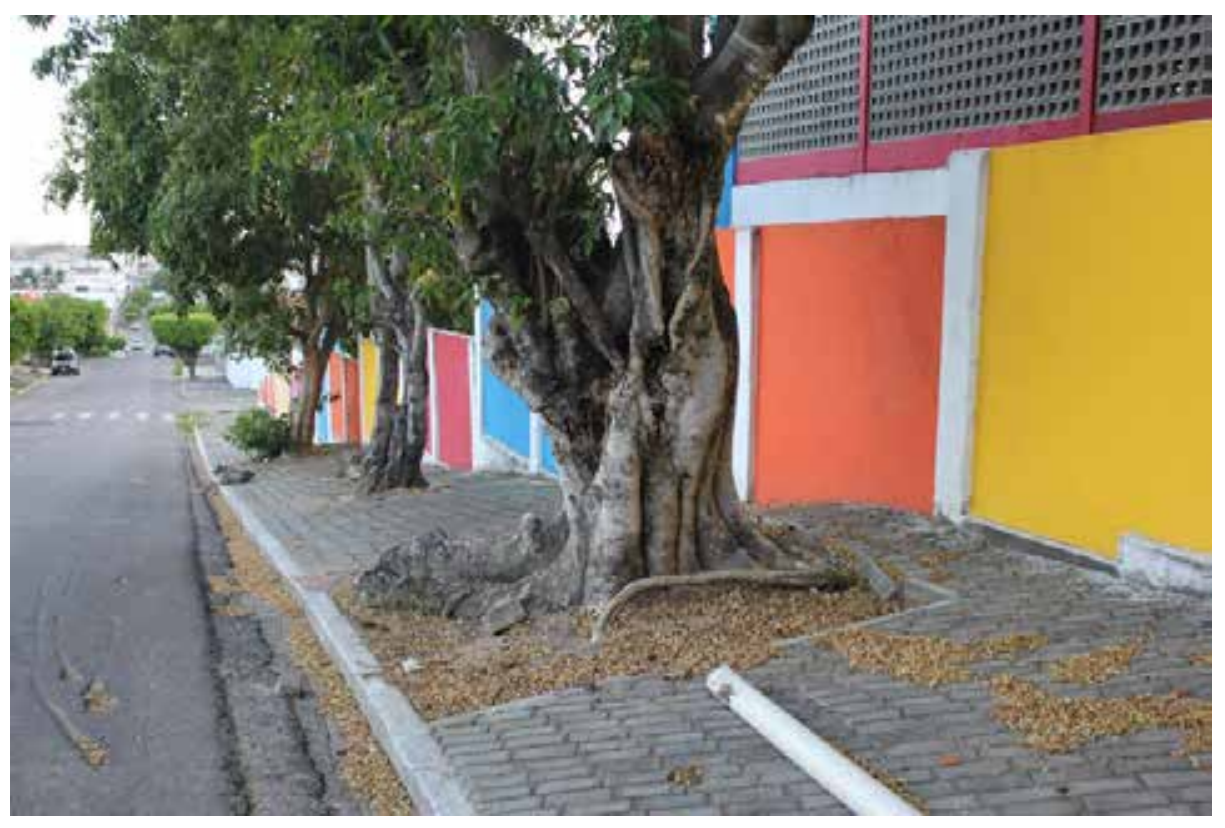

Figura 4 Sistema radicular de um Sombreiro (Clitoria fairchildiana) danificando a estrutura de uma calçada em via pública de Guarabira - PB.

Foto: Suelen Thais da Silva, 2016. 
A predominância do gênero fícus, situação comum em todos os bairros, pode ser observada na Figura 5. O cultivo predominante de plantas exóticas favorece o desequilíbrio ecológico, uma vez que a diversidade arbórea favoreceria a diversidade de espécies animais como pássaros, morcegos, insetos e polinizadores.

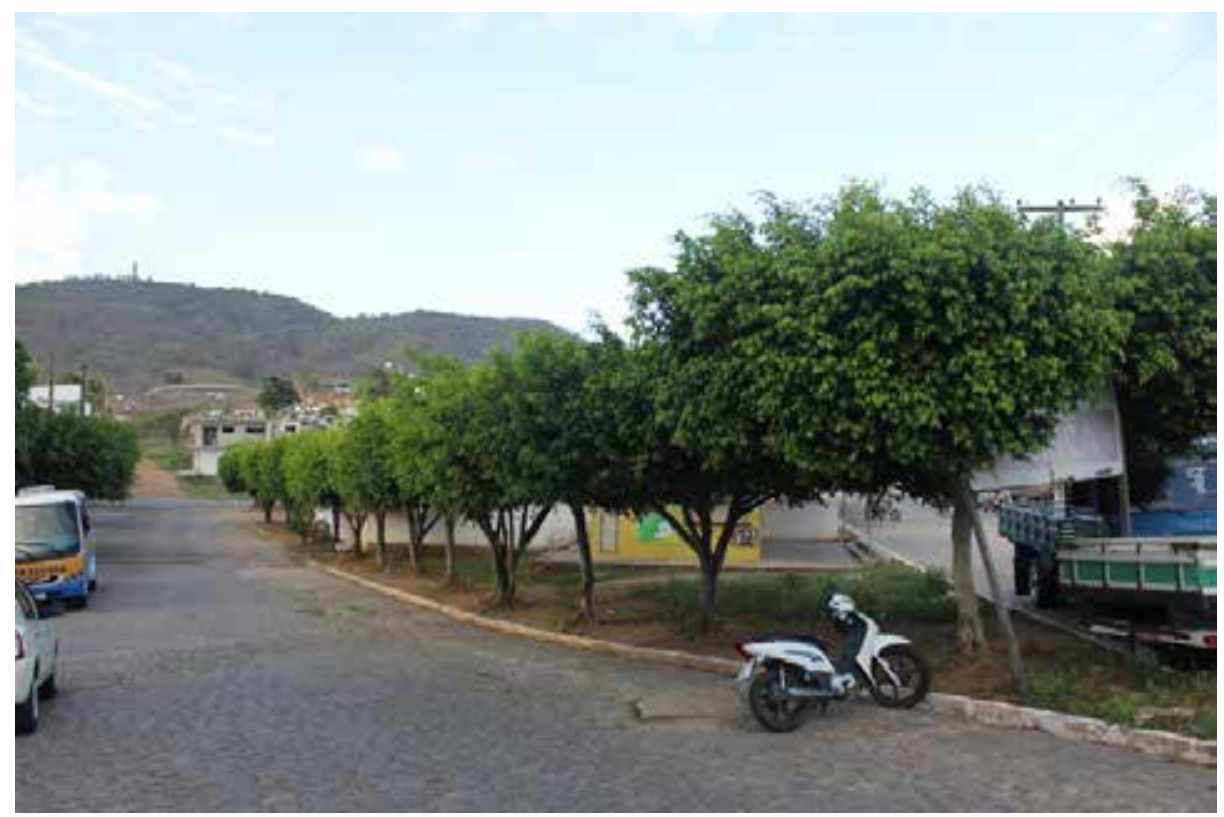

Figura 5 Vista de via pública onde é dominante a espécie Ficcus benjamina, em Guarabira - PB. Foto: Suelen Thais da Silva, 2016.

Além dos problemas já citados acima, também é possível observar o pequeno espaçamento entre as árvores e a pequena área de infiltração. Ao preparar o local para se plantar uma árvore, deve-se manter uma área livre de pavimentação que não deve ser inferior a $1,0 \mathrm{~m}^{2}$, para permitir a entrada da água da chuva, adubação e aeração do solo.

Sabe-se que para obter uma arborização urbana de qualidade, devem-se corrigir esses problemas mas, no entanto, o panorama observado na cidade de Guarabira reproduz o que se vê em outras cidades da região, a exemplo do que temos na cidade de Pombal na Paraíba, que de acordo com Crispin et al. (2014), também apresenta problemas como a predominância de espécies exóticas.

\subsection{Análise das Matrizes}

O uso da Matriz de Leopold mostrou-se eficiente por permitir a fácil sistematização de um grande número de informações em escala municipal. Mesmo sendo aplicada por amostragem, os resultados permitem a elaboração rápida de políticas públicas voltadas para a melhoria da arborização urbana. Além disso, o uso da matriz permitiu uma análise qualitativa dos danos ambientais e infraestruturais causados pela má arborização ou por sua ausência. Essa informação pode se somar a outras meto- 
dologias, como a que foi proposta por Sartori e Balderi (2009), que apresentaram um índice de danos à infraestrutura das cidades causados pela arborização que permite uma avaliação quantitativa e econômica dos danos, mesmo que limitada apenas ao aspecto infraestrutural.

A Figura 6 corresponde a matriz aplicada nas ruas do bairro São José, equivalente ao utilizado nos demais bairros analisados. Para cada interação entre a arborização e os elementos ambientais (ação $x$ fator) existem dois quadros, o primeiro à esquerda corresponde à magnitude do impacto, o segundo corresponde a sua importância relativa.

No bairro São José observa-se que os principais problemas referentes à arborização estão: na pequena quantidade de árvores (-4); porte avantajado para o local (-10); local de plantação inadequado para o porte da árvore (-15); podas não realizadas (-16); o espaçamento adensado entre as árvores (-18); raízes provocando danos (18); a baixa diversidade (-56) e predominância de plantas exóticas (-64).

A baixa quantidade de árvores afeta negativamente o conforto térmico do bairro, bem como a qualidade do ar e a beleza da paisagem. Ao mesmo tempo, essa condição da arborização afeta positivamente a eficiência da iluminação pública e a maior visibilidade das ruas. Entretanto, nas ruas onde há presença adensada da arborização, esses dois últimos fatores urbanos são afetados negativamente por prejuízos na iluminação, na visibilidade da via e de placas de sinalização.

Dessa forma, ao considerar um determinado fator urbano como "iluminação públi$\mathrm{ca}^{\prime \prime}$, observa-se que ele é ponderado positivamente quando interage com a ausência de árvores, ou mesmo com a presença delas dispostas de forma planejada e estratégica, ou é ponderado negativamente quando interage com a presença desordenada da arborização, refletindo a diversidade de situações que se pode encontrar em um mesmo bairro.

A baixa diversidade de plantas no Bairro São José torna a paisagem monótona, predominando o Fícus e o Nim, causando danos à infraestrutura, uma vez que as copas das árvores estão sempre em contato com a fiação.

Com base nas análises obtidas através da matriz aplicada ao Bairro Novo, podese observar que o mesmo apresenta algumas características semelhantes ao bairro supracitado, mas, no entanto: as raízes provocando danos (-23); a predominância de espécies exóticas (-65) e baixa diversidade de plantas (66) são as que mais afetam as condições urbanas desse bairro.

Durante as pesquisas foi observado que o Bairro Novo apresenta uma maior quantidade de árvores se comparado aos demais, entretanto, as espécies arbóreas são em sua totalidade exóticas e apresentam problemas constantes de podas não realizada (21), ocasionando contato com a rede elétrica e problemas de espaçamento adensado (-23) afetando diretamente a estrutura das calçadas.

No bairro da Esplanada, onde a arborização é escassa, os resultados obtidos nas médias finais da matriz são: pequena quantidade de árvore (-2); podas não realizadas (10); porte avantajado para o local (10); local de plantio inadequado (-13); raízes provocando danos (-14); baixa diversidade (-67) e predominância de espécies exóticas 
(-67). Desse modo pode ser compreendido que os fatores da arborização urbana que mais causam danos ao meio urbano são a baixa diversidade e a predominância de espécies exóticas. Ambas afetam diretamente aos pássaros e polinizadores bem como a valorização da fauna local e a beleza da paisagem.

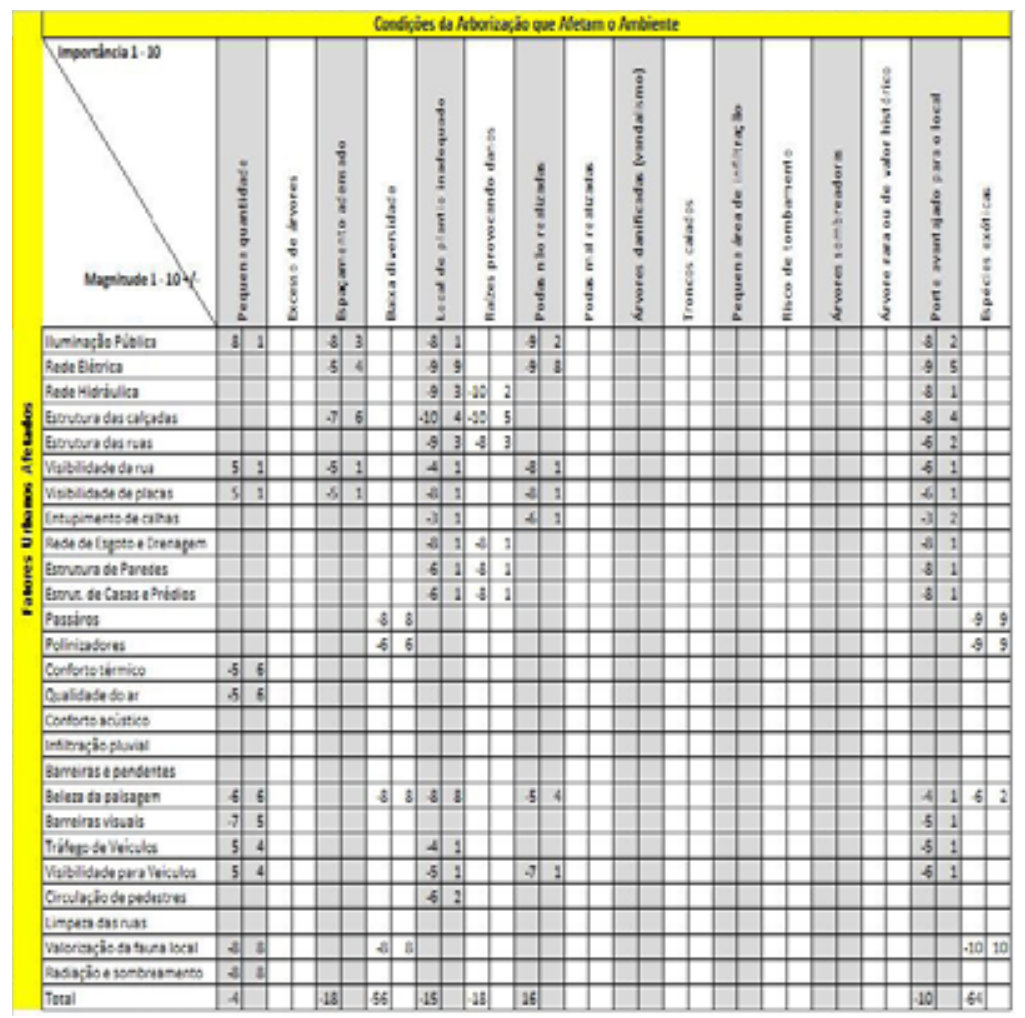

Figura 6 Matriz de Leopold aplicada ao Bairro São José, em Guarabira - PB, na avaliação ambiental da arborização urbana municipal.

Desenvolvida por Suelen Thais da Silva e Breno Henrique de Sousa, 2016.

O Bairro do Nordeste é o que se destaca por ser o menos arborizado (5). $O$ bairro tem uma praça central que é bastante arborizada, no entanto nas demais ruas quase não existem árvores e as poucas ruas arborizadas apresentam problemas como: porte avantajado para o local (11); raízes provocando danos (-17); local de plantio inadequado (25); podas não realizadas (-25); predominância de espécies exóticas (62) e a baixa diversidade (-85).

No Bairro do Centro foram analisados os canteiros centrais da Praça Lima e Moura, localizada na extensão da Rua Epitácio Pessoa. Dentre os demais bairros visitados e analisados, o Centro é o que apresenta maior quantidade de árvores (-11) a ponderação negativa ocorre porque a arborização é mal planejada causando interações negativas com a infraestrutura urbana. Destacam-se também os quesitos: árvores danificadas (24) e árvores de valor histórico (30); porém se iguala aos demais bairros no quesito espécies exóticas (48). A Praça Lima e Moura apresenta uma maior diversidade arbórea, no entanto todas são exóticas. Existem também árvores centenárias, que estão 
presentes na cidade desde a sua fundação, essas, por sua vez, afetam positivamente a beleza da paisagem, além de criarem barreiras que atenuam a polvição visual.

Observa-se que em toda a área urbana municipal sobressai-se a monotonia da paisagem dominada por poucas espécies exóticas, especialmente o gênero fícus. Algumas intervenções simples como a elaboração de cartilhas instrutivas, distribuição de mudas ou sementes pode ter impacto positivo sobre a arborização desde que essas ações sejam repetidas periodicamente, o que pode ser realizado em datas especiais como a semana do meio ambiente e o dia da árvore. Essas ações podem ser realizadas especialmente em escolas do ensino básico e fundamental, acompanhadas de ações educativas como plantio de árvores. Outras entidades civis como associações de moradores, escoteiros e grupos ecológicos devem ser envolvidas nessas ações evitando a dependência exclusiva da iniciativa pública governamental.

Este trabalho revela informações importantes para o planejamento dessas intervenções. A metodologia aqui proposta deve ser testada e aperfeiçoada a partir de sua aplicação em outras realidades. As relações entre ações e fatores devem ser constantemente discutidas e as equipes de avaliação precisam ser compostas por profissionais de diversas áreas, incluindo alguns que conheçam a área de estudo. $\bigcirc$ envolvimento da população permitirá identificar a percepção da comunidade sobre a paisagem urbana e qual poderá ser o protagonismo dos cidadãos nas intervenções sobre a mesma. Por último, e não menos importante, é o apoio e envolvimento do poder público, geralmente pouco comprometido com esse tema. Um caminho possível para sensibilizar os agentes públicos é demonstrar os prejuízos econômicos causados por uma má arborização sobre a infraestrutura urbana, bem como o potencial positivo da arborização que pode reverter-se em economia no âmbito da saúde pública por proporcionar bem-estar na população.

\section{CONCLUSÃO}

A Matriz de Leopold utilizada para avaliação da arborização urbana se mostrou um instrumento promissor na gestão de informações sobre o estado da arte da arborização municipal. A ferramenta permitiu diagnosticar de forma rápida e econômica aspectos urbanos e ambientais afetados pela ausência da arborização ou por sua presença desordenada.

Diante dos resultados obtidos, é de fácil percepção que a cidade de Guarabira apresenta uma arborização de baixa qualidade. Entre os diversos problemas observados, pode-se destacar a baixa diversidade de plantas e a predominância de espécies exóticas que são decorrentes da falta de planejamento e repertório projetual que resulta em uma arborização desordenada, inapropriada e descontínua. Assim, uma arborização urbana não planejada afeta não apenas ao meio ambiente, mas também à infraestrutura urbana, causando prejuízos econômicos e diminuindo a qualidade de vida dos seus habitantes.

Ainda com base nos resultados obtidos é possível concluir que todos os bairros analisados apresentam problemas semelhantes referentes às condições da arborização, 
sendo eles: a baixa diversidade, local de plantio inadequado e a predominância das espécies exóticas. Tais problemas podem ser sanados através da realização de um planejamento da arborização urbana.

É imprescindível que seja realizado um planejamento da arborização da cidade de Guarabira, a fim de implantar projetos que utilizem árvores nativas e de porte compatível com a infraestrutura urbana (rede elétrica, hidráulica, calçadas, etc.) bem como evitar gastos e transtornos desnecessários, permitindo assim que a população desfrute de uma arborização de melhor qualidade.

\section{REFERÊNCIAS BIBLIOGRÁFICAS}

BRASIL. Ministério do Meio Ambiente, Conselho Nacional de Meio Ambiente, CONAMA. Resolução CONAMA $N^{\circ}$ 001/86, de 23 de janeiro de 1986 - in: Resoluções, 1986.

CAMPOS, V. F.. Controle da qualidade total (no estilo japonês). Fundação Cristiano Ottoni, Escola de engenharia da UFMG. Belo Horizonte, 1992.

CEMIG - Companhia Energética de Minas Gerais. Manual de arborização. Belo Horizonte: Cemig / Fundação Biodiversitas, 2011. $112 \mathrm{p}$.

COSTA, M. V.; CHAVES, P. S. V.; OLIVEIRA, F. C.. Uso das técnicas de avaliação de impacto ambiental em estudos Realizados no Ceará. In: XXVIII Congresso Brasileiro de Ciências da Comunicação, Anais INTERCON, Rio de Janeiro, 2005.

CRISPIM, D. L.; SILVA, M. A.; CHAVES, A. D. C. G.; ALMEILDA, Ricardo R. P.; FREITAS, A. J. F.. Diagnóstico da arborização urbana do centro da cidade de Pombal-PB. In: Revista Verde (Mossoró - RN), v. 9, n.1, p.191-196, jan - mar, 2014.

DELLARETTI, O. F.. As sete ferramentas do planejamento da qualidade. Fundação Cristiano Ottoni, Escola de engenharia da UFMG,1996. 183 p.

FARAH, I. M. C.. Arborização urbana e sua inserção no desenho urbano. In: Boletim Informativo da Sociedade Brasileira de Arborização Urbana. V.7, n.3, 1999.

GRAZIANO, T. T.. Viveiros Municipais. Departamento de Horticultura - FCAVJ - UNESP. Notas de Aula, 34 p.2131, 1994.

IBGE - Instituto Brasileiro de Geografia e Estatística. Censo da População 2010. Rio de Janeiro, 2014.

LEOPOLD, L. B.; CLARKE F. E.; HANSHAW B. B.; BALSLEY J. E. A procedure for evaluating environmental impact. U.S. In: Geological Survey, Circular 645, Washington, D.C, 1971.

LOBODA, C. R.; ANGELIS, B. L. D. Áreas verdes públicas urbanas: conceitos, usos e Funções. In: Ambiência, Guarapuava, PR, v.1 n.1 p. $125139,2005$.

LORENZI, H.. Árvores Brasileiras. Manual de identificação e cultivo de plantas arbóreas nativas do Brasil. 5.ed. Nova Odessa: Editora Plantarum, v.1. São Paulo: 2008.

MENEGHETTI, G. I. P. Estudo de dois métodos de amostragem para inventário da arborização de ruas dos bairros da orla marítima do município de Santos, SP. 114 f. Dissertação (Mestrado em Recursos Florestais, Silvicultura e Manejo Florestal) Escola Superior de Agricultura Luiz de Queiroz, Universidade de São Paulo, Piracicaba, 2003.

MOREIRA, I. V. D. Origem e Síntese dos Principais Métodos de Avaliação de Impacto Ambiental (AIA): Manual de Avaliação de Impactos Ambientais. Curitiba: Surehma/GTZ, 1992.

PIRES, A. P. Amostragem e pesquisa qualitativa: ensaio teórico e metodológico. In: POUPART, J. et al. A Pesquisa qualitativa: Enfoques epistemológicos e metodológicos. 2. ed. Petrópolis: Vozes, 2010. Cap. 5. p. 155-211.

PONCE, D. V. La matriz de Leopold para la evaluación del impacto ambiental. Recuperado de http://ponce. sdsu. edu/la_matriz_de_leopold. html, 2011.

SANCHOTENE, M. C. C. Desenvolvimento e perspectivas da arborização urbana no Brasil. In: Congresso Brasileiro de Arborização Urbana, 2, 1994. São Luís - Ma. Anais. São Luís, Sociedade Brasileira de Arborização Urbana; 1994 
SANTOS, N. R. Z.; TEIXEIRA, Í. F. Arborização de vias públicas: Ambiente x Vegetação. Instituto Souza Cruz, $1^{a}$ ed. Porto Alegre: Ed. Pallotti. 2001.

SARTORI, R. A.; BALDERI, A. P. Inventário da arborização urbana do município de Socorro - SP e proposta de um índice de danos à infraestrutura das cidades. In: Revista da Sociedade Brasileira de Arborização Urbana, Piracicaba - SP, v.6, n.4, p.68-89, 2011.

SEGAWA, H. Ao amor do público: jardins no Brasil. São Paulo: Studio Nobel, 1996.

SHAMS, J. C. A.; GIACOMELI, D. C.; SUCOMINE, N. M. Emprego da Arborização na Melhoria do Conforto Térmico nos Espaços Livres Públicos. In: REVSBAU, Piracicaba - SP, v.4, n.4, p.1-16, 2009.

SILVA, L. F.; LIMA, A. M. L. P.; SILVA, D. F. F.; COUTO, H. T. Z. Interceptação da chuva pelas copas das espécies de Caesalpinia pluviosa DC.(Sibipiruna) e Tipuana tipu O. Kuntze (Tipuana) em arborização urbana. In: Scientia Forestalis, Piracicaba, v. 36, n. 80, p. 307 315, dez. 2008. 